\title{
Prevalence of subclinical mastitis in dairy farms in urban and peri-urban areas of Kampala, Uganda
}

\author{
Markus Abrahmsén - Ylva Persson • \\ Benon Mbabazi Kanyima • Renée Båge
}

Accepted: 30 July 2013 /Published online: 17 August 2013

(C) The Author(s) 2013. This article is published with open access at Springerlink.com

\begin{abstract}
It is widely recognized that subclinical mastitis (SCM) is an extensive problem in the dairy industry worldwide. It is of particular concern in developing countries. The aim of this study was to establish the prevalence of SCM in dairy cattle in the urban and peri-urban areas of Kampala, Uganda and to gain information about pathogens and antibiotic resistance patterns. The study was conducted as a field study in 18 smallholder dairy farms in peri-urban Kampala, Uganda. All cows at the farms were physically examined, and cows with signs of clinical mastitis were excluded. Cows $(n=195)$ were tested with California Mastitis Test (CMT), and udder quarters with CMT score $\geq 3$ (scale 1-5) were milk sampled for bacteriological analysis. To allow further sub-analysis of the results, the stage of lactation, parity, milk production, production type, udder hygiene, and cow breed were recorded. Results indicate that $86.2 \%(n=168)$ of the tested cows had SCM in one or more quarters. The most common bacteriological outcome was infection with coagulase-negative staphylococci (54.7\%), followed by negative growth $(24.9 \%)$ and streptococci $(16.2 \%)$; all of which $(n=34)$ were sensitive to penicillin. Of the tested staphylococci $(n=17)$, the majority $(58.9 \%)$ were positive for penicillinase production. Factors with significant impact on the prevalence of SCM at cow level were the stage of
\end{abstract}

M. Abrahmsén $(\bowtie) \cdot$ R. Båge

Division of Reproduction, Department of Clinical Sciences, Faculty of Veterinary Medicine and Animal Science, Swedish University of Agricultural Sciences, Uppsala, Sweden

e-mail: markus.abrahmsen@hotmail.com

Y. Persson

Department of Animal Health and Antimicrobial Strategies, National

Veterinary Institute/Swedish Dairy Association, Uppsala, Sweden

B. M. Kanyima

College of Veterinary Medicine, Animal Resources and Biosecurity, Makerere University, Kampala, Uganda lactation, parity, and production type. The results suggest that the prevalence of SCM in Uganda is substantially higher than reported in previous studies and in other comparable developing countries. This implies that SCM deserves more attention and that improvement in dairy cow husbandry in terms of hygiene and management is necessary.

Keywords Udder health · Smallholder dairy farming · Holstein-Friesian cows · East Africa

\section{Introduction}

Several recent reports indicate that the production of meat and milk in the developing world has doubled in recent decades, as a result of increasing demands (Food and Agriculture Organization of the United Nations (FAO) 2011a). This socalled livestock revolution provides income, employment, and high-quality nutrition, and the trend is expected to continue. Milk and other dairy products represent a very important energy source for many people and contribute to a substantial portion of the total energy intake. Infectious diseases, like mastitis, among cattle however represent a serious potential constraint to further the development of smallholder dairy cow production in developing countries and might drive rural smallholders into chronic poverty and/or starvation. In the example Uganda, the agriculture sector is the most important sector in terms of labor capacity utilization rate (FAO 2011a). The country has a population of almost 34 million people, and out of these, almost $74 \%$ work in the agricultural sector (Uganda Bureau of Statistics, report 2008). Despite the fact that Uganda is, in most parts, a very fertile country, about $21 \%$ of Ugandans suffer from undernourishment (FAO 2011a). This underlines the need for increased agricultural production in the country, in which milk production plays a key role (FAO 2011c). 
Several different studies point out that subclinical mastitis (SCM) is more economically important than clinical mastitis (CM) (Godkin et al. 1990; Kader et al. 2003; Joshi and Gokhale 2006; Seegers et al. 2003; Singh and Sing 1994). This is explained by the fact that SCM is more difficult to diagnose and therefore usually persists longer in the herds, causing production losses. As any infectious disease, SCM can have many different consequences, of which two have been pointed out: (1) reduced herd population by death or culling and (2) reduced production and income (FAO 2011c). According to Hogan (2005), there might also be potential food safety risks indirectly associated with high SCC, such as ingestion of potentially pathogenic microorganisms (especially if the milk is not pasteurized), bacterial toxins, and/or antibiotic residues. The lower quality and the diminished sustainability of milk with a high SCC both constitute a potential health risk and also affect the possibility of producing other dairy products, e.g., cheese and yoghurt (Andersson et al. 2011). Hence, the prevalence, diagnosis, and treatment of SCM are very important fields both in terms of veterinary medicine and economy of developing countries.

According to previous studies in Uganda, the prevalence of SCM in Ugandan dairy cattle is substantial (OkelloUma and Gibson 1976; Nakavuma et al. 1994; Kintu et al. 2000; Byarugaba et al. 2008). For example, Byarugaba et al. (2008) reported an overall cow level prevalence of SCM at $37.2 \%$ in the Jinja Province in Uganda. Studies of prevalence and incidence of dairy cow SCM performed in other African developing countries also show a considerable prevalence. For example, Bitew et al. (2010) and Mungube et al. (2005) reported an overall prevalence of SCM at 25.2 and $52.3 \%$ at cow level and 12.3 and $32.4 \%$ at quarter level in ethiopian Holstein crossbred cows and indigenous breeds, respectively. Harouna et al. (2009), in peri-urban Hamdallaye, Niger, showed that the prevalence rate of SCM ranged between 27.1 to $55.2 \%(p<0.05)$ between dry and rainy seasons. In Tanzania, Mdegela et al. (2009) noted prevalence rates in the range of $51.6 \%$ at cow level and $30.0 \%$ at quarter level for both $\mathrm{CM}$ and SCM among smallholder cows.

Since the most common cause of mastitis in dairy cattle is bacterial infection, antibiotic therapy is an important tool in the control of mastitis. However, misuse of antibiotics poses great risk of spreading antibiotic resistance among bacteria. Hence, antibiotic treatment of SCM is generally recommended only during drying off and not during lactation (SVS 2011), albeit other policies exist. For mastitis, as for most other illnesses, resistance is not due to mutations as much as the spread of resistant bacteria and resistance genes-yet another reason to keep the prevalence of SCM and CM low. Given this, the main purpose of this study was to investigate the prevalence of SCM in dairy cattle in the urban and periurban areas of Kampala, based on California Mastitis Test (CMT), and furthermore to gain information about pathogens, antibiotic resistance patterns, different risk factors, and possibilities of future prevention.

\section{Materials and methods}

\section{Study design}

The study has been approved and performed in accordance with the ethical standards of the policy of the Institutional Review Board (ref. no. VAB/REC/11/115) of the School of Veterinary Medicine and Animal Resources, Makerere University. It was conducted within a $20-\mathrm{km}$ radius of Kampala during October 2011. The study populations were lactating cows of all parities on 18 smallholder farms. All cows were hand milked twice daily. The herd size of the farms ranged from 1 to 34 cows. A total of 195 lactating cows were included in the study. The distribution of breeds included in the study was 101 Holstein-Friesian cows, 70 Holstein-Friesian/ local crossbreed cows, 18 Jersey/Guernsey cows, and 6 other mixed breed cows.

Each farm was visited once and the cows were examined at cow and quarter level to rule out clinical mastitis (temperature $\leq 39.5^{\circ} \mathrm{C}$, no signs of illness and/or inflammatory signs of the udder, and normal milk upon ocular inspection). The cows were tested with the CMT according to Schalm and Noordlander (1957) and Mellenberger and Roth (2000) to detect the prevalence of subclinical mastitis. To allow further analysis of the results, the stage of lactation $(<$ day 60 , days 60-120, >day 120), parity (primiparous/multiparous), daily milk production $(<71,7-151,>151$; according to information from the farmer), grazing system (zero grazing/open grazing), udder hygiene (good/poor), and cow breed (Holstein-Friesian/ other breeds) were also recorded.

The CMT test result was scored from 1 to 5 according to the Scandinavian scoring system, where 1 is negative result (no gel formation), 2 is traceable (possible infection), and 3 or above indicates a positive result, where 5 has the most gel formation (Saloniemi 1995). All quarters with CMT $\geq 3$ were milk sampled during ongoing milking, for further bacterial examination. The sampling was carried out according to the method recommended by the National Mastitis Council (NMC 2004). After collection, the milk samples were transported in an ice-cooled box and later transferred into a fridge at $4{ }^{\circ} \mathrm{C}$. Milk samples were then processed within $24 \mathrm{~h}$ after their collection and cultured.

The milk samples were analyzed at the microbiology laboratory, Faculty of Veterinary Medicine, Makerere University, Kampala. Ten microliters of each milk sample was spread on blood agar plates ( $5 \%$ bovine blood). The plates were then put into aerobic incubators at $37^{\circ} \mathrm{C}$ for $16-24 \mathrm{~h}$, where plates with dubious growth were allowed an extra $24 \mathrm{~h}$ before final examination. To be classified as a positive bacterial growth, 
at least one colony-forming unit (CFU) was needed for Staphylococcus aureus and Streptococcus agalactiae and at least three CFUs for the other genera.

The bacteria on each plate were then analyzed and categorized according to colony morphology and $\alpha-, \beta-$, or double hemolysis. Depending on genera, the cultures were then categorized based on potassium hydroxide test reaction, catalase test reaction, and $\beta$-glucuronidase test reaction. $S$. aureus isolates were tested for penicillinase production, using the cefinase test. To determine the amount of bacterial growth, the amount of colonies in each sample was quantified and then put into three categories: mild growth $(<10$ colonies $)$, moderate growth (10-50 colonies), and severe growth $(>50$ colonies). If the plate had a growth of $\geq 3$ diverse bacterial agents, it was classified as mixed growth.

\section{Antibiotic susceptibility testing}

All streptococci and some staphylococci bacterial isolates were saved in agar tubes and brought to the National Veterinary Institute (SVA) in Uppsala, Sweden. Streptococci isolates were subtyped using CAMP test and 12 biochemical reactions to distinguish among $S$. agalactiae, Streptococcus dysgalactiae, Streptococcus uberis, and other Streptococcus spp. Staphylococci isolates were tested for penicillinase production, using the penicillinase test (Sensititre method) (Franklin and Wierup 1982), to distinguish if they were sensitive to benzylpenicillin or not.

Isolates of $S$. agalactiae, $S$. dysgalactiae, and $S$. uberis were tested for antimicrobial susceptibility by determination of minimum inhibitory concentration (MIC), using a micro dilution method. The testing was performed according to recommendations from the Clinical and Laboratory Standards Institute using VetMIC ${ }^{\mathrm{TM}}$ panels (National Veterinary Institute, Uppsala, Sweden) and cation adjusted Mueller-Hinton broth (Becton Dickinson, Cockeysville, USA) (Clinical and Laboratory Standards Institute 2007). The streptococci isolates were classified as susceptible or resistant based on speciesspecific epidemiological cutoff values for each type of antibiotic, issued by the European Committee on Antimicrobial Susceptibility Testing (EUCAST).

Statistical analyses

Analyses of the frequency of positive cows (at least one quarter with $\mathrm{CMT} \geq 3$ ) were first performed. The results were hereafter first analyzed by $\chi^{2}$ test for each individual factor (stage of lactation, parity, milk production, production system, udder hygiene, and cow breed). The effects of close to significant factors from the first $\chi^{2}$ analysis were further analyzed together in a multivariable analysis while using logistic models (PROC LOGISTIC, SAS version 9.2).

\section{Results}

Descriptive and statistic data

The results of the CMT screening indicate that $86.2 \%(n=195)$ of the tested cows had SCM in one or more quarters. At quarter level, the prevalence of SCM was $55.4 \%(n=760)$. No correlation was found between the prevalence of SCM and milk production and cow breed. The factors significantly linked to the prevalence are presented below.

The prevalence of SCM was analyzed on basis of stage of lactation (Table 1). The figures from the cow level results in the first $\chi^{2}$ test, in which the individual factors/marker of the frequency of positive cows (at least one quarter with CMT $\geq 3$ ), were analyzed and showed that there is a close-to-significant positive correlation for SCM and stage of lactation $(p<0.06)$. When these results then were analyzed in the second multivariable $\chi^{2}$ test, in which correlation for the effects of other factors/ markers was analyzed, it resulted in a significant $(p<0.02)$ difference between the cows, where cows with less than 60 days elapsed from last calving had a lower prevalence of SCM than cows with more than 120 days from last calving. The number of quarters with CMT scores $\geq 3 /$ cow in each subgroup of stage of lactation (Fig. 1) points in the same direction: cows with $<60$ days had 1.86 affected quarters/cow and cows with

Table 1 Factors related to the prevalence of subclinical mastitis at cow and quarter level

\begin{tabular}{|c|c|c|c|}
\hline Factors & Type & $\begin{array}{l}\text { CMT-positive } \\
\text { cows }(\%)\end{array}$ & $\begin{array}{l}\text { CMT-positive } \\
\text { quarters (\%) }\end{array}$ \\
\hline \multirow[t]{4}{*}{ Stage of lactation } & $<60$ days & $25 / 31(80.6)$ & $55 / 122(45.1)$ \\
\hline & $60-120$ days & $27 / 36(75.0)$ & $64 / 138(46.4)$ \\
\hline & $>120$ days & $107 / 119(89.9)$ & $282 / 464(60.1)$ \\
\hline & Total & $159 / 186(85.5)$ & $401 / 714(56.2)$ \\
\hline \multirow[t]{3}{*}{ Parity } & Primiparous & $38 / 48(79.2)$ & 91/190 (47.9) \\
\hline & Multiparous & $129 / 146(88.4)$ & $327 / 566(57.8)$ \\
\hline & Total & $167 / 194(86.1)$ & $418 / 756(55.3)$ \\
\hline \multirow[t]{4}{*}{ Milk production } & $>151$ & $22 / 27$ (81.5) & $62 / 108(57.4)$ \\
\hline & $7-151$ & $126 / 143(88.1)$ & $301 / 553(54.4)$ \\
\hline & $<71$ & $20 / 25(80.0)$ & $58 / 99(58.6)$ \\
\hline & Total & $168 / 195(86.2)$ & $421 / 760(55.4)$ \\
\hline \multirow[t]{3}{*}{ Cow breed } & Holstein & 88/101 (87.1) & $235 / 396(59.3)$ \\
\hline & Other breeds & 80/94 (85.1) & $186 / 364(51.1)$ \\
\hline & Total & $168 / 195(86.2)$ & $421 / 760(55.4)$ \\
\hline \multirow[t]{3}{*}{ Udder hygiene } & Good & $45 / 55(81.8)$ & $103 / 211(48.8)$ \\
\hline & Poor & $123 / 140(87.9)$ & $318 / 549(57.9)$ \\
\hline & Total & $168 / 195(86.2)$ & $421 / 760(55.4)$ \\
\hline \multirow[t]{3}{*}{ Grazing system } & Zero grazing & $22 / 23(95.7)$ & $61 / 83(73.5)$ \\
\hline & Grazing & $119 / 142(83.8)$ & $301 / 560(53.8)$ \\
\hline & Total & $141 / 165(85.5)$ & $362 / 643(56.3)$ \\
\hline
\end{tabular}

CMT California Mastitis Test 
Fig. 1 Quarters with California Mastitis Test score $\geq 3 /$ cow in the subgroups of stage of lactation. The columns describe the mean number of quarters with California Mastitis Test (CMT) score $\geq 3 /$ cow of all cows in each subgroup of stage of lactation with error bars showing \pm 2 standard derivations. $D=$ days

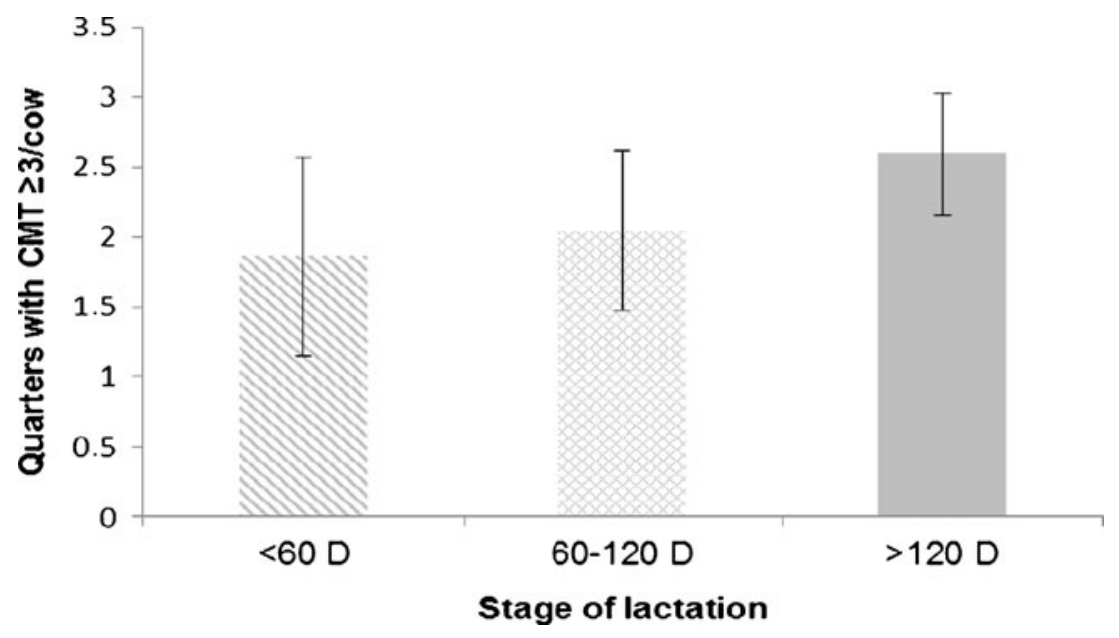

$>120$ days had 2.59 affected quarters/cow, which is close to significance $(p<0.06)$.

The prevalence of SCM was also analyzed on the basis of parity (Table 1$)$. When the results were analyzed in the second multivariable $\chi^{2}$ test, it showed a strong significance $(p<0.02)$, where primiparous cows had a lower prevalence of SCM than multiparous cows.

Looking at the number of quarters with $\mathrm{CMT} \geq 3 /$ cow, analyzing the udder hygiene of just Holstein-Friesian (HF) cows in each subgroup, HF with good hygiene had 1.63 quarters/cow and cows with poor hygiene had 2.72 quarters/cow. This is also a significant correlation $(p<0.003)$. There was no such significant correlation for the group other breeds.

The last factor analyzed was SCM on the basis of production system (Table 1). When analyzing the figures from the cow level result in the first $\chi^{2}$ test, there was a tendency of significant correlation ( $p=0.13$ ) between SCM and cow production system, where grazing cows had a lower prevalence.

\section{Distribution of udder pathogens}

The most common bacteriological outcome was infection with coagulase-negative staphylococci $(54.7 \%)$, followed by negative growth (24.9\%), streptococci (16.2\%), mixed growth (1.6\%), Escherichia coli $(1.3 \%)$, and S. aureus (0.9\%). Of the 73 strains of streptococci, 48 were subtyped. Out of this, the distribution was $15 \mathrm{~S}$. agalactiae, $12 \mathrm{~S}$.dysgalactiae, $7 \mathrm{~S}$. uberis, and 14 other streptococci species.

\section{Antimicrobial susceptibility testing}

The results from the streptococci susceptibility test are shown in Table 2. Final concentrations of antibiotics ranged from $\leq 0.03$ to $64 \mathrm{mg} / \mathrm{l}$. One hundred percent of the tested streptococci $(n=34)$ were sensitive to penicillin (Table 2). Of the tested staphylococci, six out of nine CNS were positive for penicillinase production in the penicillinase test carried out at SVA and four out of four $S$. aureus were tested positive. Of the four cefinase-tested $S$. aureus in Uganda, all four were negative for penicillinase production.

\section{Discussion}

The overall prevalence of SCM is unexpectedly high. This applies especially to the prevalence at cow level, where Byarugaba et al. (2008) reported an overall cow level prevalence of SCM at $37.2 \%$ in their study from the Jinja Province in Uganda. Studies from other countries using similar criteria to characterize a cow as SCM positive or not (Bitew et al. 2010; Gianneechini et al. 2002; Harouna et al. 2009; Joshi and Gokhale 2006; Mdegela et al. 2009; Mungube et al. 2005; Rabbani and Samad 2010) reported prevalence rates ranging from 25.2 to $55.2 \%$ at cow level. A possible explanation to the high prevalence of SCM found around Kampala could be that risk factors contributing to SCM were more predominant, e.g., a high proportion of cow confinement in zero grazing production system, a high proportion of poor udder hygiene practices, and a higher proportion of cows in late parity and in late stages of lactation.

The bacterial findings, however, resembled, but were not identical to the findings of earlier studies reported from Uganda (Byarugaba et al. 2008) and other developing countries (Bitew et al. 2010; Rabbani and Samad 2010); Harouna et al. 2009)).

Analyzing the antibiotic resistance pattern of this study, it seems that the tested streptococci spp. required a higher MIC of tetracycline and trimethoprim, but required similar MIC of penicillin in comparison to the results of a Swedish study (Persson et al. 2011). However, this study considered only $S$. dysgalactiae and $S$. uberis, making it difficult to compare the resistance pattern of $S$. agalactiae. For some bacteria/antibiotic combinations, there are no EUCAST epidemiological cutoff values, i.e., the bacteria have not been classified as susceptible or resistant to certain antibiotics. There are other imaginable ways to determine the antibiotic susceptibility for these bacteria, e.g., 
Table 2 Resistance and distribution of minimum inhibitory concentration (MIC) for Streptococcus agalactiae $(n=15)$, Streptococcus dysgalactiae $(n=7)$, and Streptococcus uberis $(n=12)$

\begin{tabular}{|c|c|c|c|c|c|c|c|c|c|c|c|c|c|c|}
\hline \multirow[b]{2}{*}{ Substance } & \multirow[b]{2}{*}{ Species } & \multirow[b]{2}{*}{$\begin{array}{l}\text { Resistance } \\
(\%)\end{array}$} & \multicolumn{12}{|c|}{ Distribution (number of isolates) of MICs (mg/l) } \\
\hline & & & $\leq 0.03$ & 0.06 & 0.12 & 0.25 & 0.5 & 1 & 2 & 4 & 8 & 16 & 32 & $>64$ \\
\hline \multirow{3}{*}{ Cefalothin } & S. agal. & 0 & & 3 & 6 & 6 & & & & & & & & \\
\hline & S. dysg. & - & & & 6 & 7 & & & & & & & & \\
\hline & S. uberis & - & & & 9 & 2 & & 1 & & & & & & \\
\hline \multirow{3}{*}{ Clindamycin } & S. agal. & 0 & & & & 15 & & & & & & & & \\
\hline & S. dysg. & 0 & & & & 7 & & & & & & & & \\
\hline & S. uberis & - & & & & 12 & & & & & & & & \\
\hline \multirow{3}{*}{ Ciprofloxacin } & S. agal. & 0 & & & & & 3 & 12 & & & & & & \\
\hline & S. dysg. & - & & & & & 3 & 4 & & & & & & \\
\hline & S. uberis & - & & & & & 7 & 5 & & & & & & \\
\hline \multirow{3}{*}{ Chloramphenicol } & S. agal. & - & & & & & & & 11 & 4 & & & & \\
\hline & S. dysg. & - & & & & & & 1 & 3 & 3 & & & & \\
\hline & S. uberis & - & & & & & & & 2 & 10 & & & & \\
\hline \multirow{3}{*}{ Erythromycin } & S. agal. & 0 & & & & 15 & & & & & & & & \\
\hline & S. dysg. & - & & & & 7 & & & & & & & & \\
\hline & S. uberis & - & & & & 12 & & & & & & & & \\
\hline \multirow{3}{*}{ Fusidine } & S. agal. & 0 & & & & & & & & & 15 & & & \\
\hline & S. dysg. & - & & & & & & 1 & 3 & 1 & 2 & & & \\
\hline & S. uberis & - & & & & & & & & & 12 & & & \\
\hline \multirow{3}{*}{ Gentamicin } & S. agal. & - & & & & & & 1 & 5 & 5 & 4 & & & \\
\hline & S. dysg. & - & & & & & & 2 & 4 & 1 & & & & \\
\hline & S. uberis & - & & & & & & & 2 & 5 & 5 & & & \\
\hline \multirow{3}{*}{ Kanamycin } & S. agal. & - & & & & & & & & & 3 & 4 & 8 & \\
\hline & S. dysg. & - & & & & & & & & & 2 & 4 & 1 & \\
\hline & S. uberis & - & & & & & & & & & 1 & 5 & 6 & \\
\hline \multirow{3}{*}{ Oxacillin } & S. agal. & - & & & 2 & 6 & 6 & 1 & & & & & & \\
\hline & S. dysg. & - & & & 7 & & & & & & & & & \\
\hline & S. uberis & - & & & 4 & 8 & & & & & & & & \\
\hline \multirow{3}{*}{ Benzylpenicillin } & S. agal. & 0 & 3 & 7 & 5 & & & & & & & & & \\
\hline & S. dysg. & 0 & 7 & & & & & & & & & & & \\
\hline & S. uberis & - & 7 & 4 & & 1 & & & & & & & & \\
\hline \multirow{3}{*}{ Tetracycline } & S. agal. & 100 & & & & & & & & & 1 & 1 & 4 & 9 \\
\hline & S. dysg. & - & & & & & & & & 1 & 2 & 1 & 3 & \\
\hline & S. uberis & - & & & & & 12 & & & & & & & \\
\hline \multirow{3}{*}{ Trimethoprim } & S. agal. & - & & & & & & & 1 & 4 & 5 & 4 & 1 & \\
\hline & S. dysg. & - & & & & & & 2 & 4 & 1 & & & & \\
\hline & S. uberis & - & & & & & & & 7 & 3 & 2 & & & \\
\hline
\end{tabular}

MICs minimum inhibitory concentrations, S. agal. Streptococcus agalactiae, S. dysg. Streptococcus dysgalactiae, S. uberis Streptococcus uberis White fields denote range of dilutions tested for each substance. MICs above the range are given as the concentration closest to the range. MICs equal to or lower than the lowest concentration tested are given as the lowest tested concentration. Bold vertical lines indicate the European Committee on Antimicrobial Susceptibility Testing (EUCAST) epidemiological cutoff values. When no cutoff value is available, isolates are not classified as susceptible or resistant 
cutoff values from other sources and/or clinical evaluation of antibiotic treatment. However, since the main reason of this study was not to provide recommendations of antibiotic treatment, nor evaluate the effect of such, this will not be further discussed.

Comparatively, the penicillin resistance of CNS and S. aureus seems to be higher in Uganda than the one obtained in Sweden: 6/9 resistance test for CNS and 4/8 resistance tests for $S$. aureus were positive, respectively. Still, this comparison has limitations, since the number of tested CNS and $S$. aureus is limited in this study. In addition, all (three) of the $S$. aureus cultures tested in Uganda showed to be penicillinase negative, whereas four out eight of the samples tested in Sweden were resistant to penicillin - an observation that might question the accuracy of the cefinase test. Yet, the high resistance pattern of staphylococci observed in this study is still cause for worry. In their Ugandan study, Byarugaba et al. (2008) also showed a high penicillin resistance among staphylococci, namely $86.6 \%$.

A plausible reason of the high antibiotic bacterial resistance in Uganda could be due to that the dairy farms do not consistently test cows to identify which ones to cull if found penicillinase positive. This could in turn explain the prevalence of udder infections with resistant bacteria of newly arrived cows. Another reason could be that farmers are able to obtain antibiotics over the counter without prescription. This laxity increases the risk of antibiotic misuse, which in turn may contribute to the development of antibiotic resistance (Byarugaba 2004; Byarugaba et al. 2008). Nonetheless, SCM in Uganda still seems to be treatable with penicillin during the dry period in most cases - a fact illustrated by the observation that $100 \%$ of the examined streptococci were sensitive to benzylpenicillin.

The explicit significance regarding the stage of lactation, where cows with less than 60 days from the last calving date have a lower prevalence and a lower number of udder parts with $\mathrm{CMT} \geq 3 /$ cow than cows with more than 120 days past from last calving, is somewhat as expected. The udder is most sensitive to acute $\mathrm{CM}$ and SCM during the period after the calving, whereas chronic mastitis, most often subclinical, is more frequent later during the lactation. At the visited farms, the use of dry period was almost non-existing. Hence, some cows could be milking for a very long time, up to several years, increasing the risk of SCM. The tradition of not using dry periods might be one explanation to the figures implying that cows in late lactation were more susceptible to SCM.

In terms of parity, primiparous cows had a lower prevalence and a lower number of quarters with CMT $\geq 3 /$ cow than multiparous cows. This is as expected. Joshi and Gokhale (2006) and Byarugaba et al. (2008) also found that the prevalence of SCM increased with increasing parity, and Rabbani and Samad (2010) presented similar results in their Bangladeshian study. Older cows are more susceptible to SCM (Biaffa et al. 2005 in Neelesh et al. 2012) because of the breakdown of the streak canal barriers and udder tissue with progressive ageing process (Schalm et al. 1971).
Also, the clear significance regarding udder hygiene was expected. HF cows with poor udder hygiene had a higher amount of CMT $\geq 3 /$ cow, compared to HF cows with good udder hygiene. A dirty udder is more susceptible to SCM. Grazing cows on pasture, which have better conditions to maintain good udder hygiene, have a tendency of lower prevalence than zero grazing cows. This has also been shown in an earlier Ugandan study, where poor udder hygiene, western breed, and zero grazing were particularly pointed out as contributing factors for a high prevalence of SCM (Byarugaba et al. 2008).

The reason to this high prevalence of SCM is multifaceted, but there are a few anticipatory mechanisms deserving particular elucidation. Looking at the impact of certain factors, such as zero grazing, late stage of lactation, high parity, and poor udder hygiene, all seem to increase the risk of getting SCM.

Even though we did not perform any statistics on it, a reflection is that the overall hygiene and especially the hygiene routines around milking time are the main reasons of the high prevalence. Also, we did not observe the use of grouping the cows or milking them in a predetermined order, according to their udder status.

The results of this study provide new information and will hopefully contribute to a possibly lower prevalence of SCM in the future. The results also suggest that it is important to work with preventive work in the farms, in order to lower the prevalence of SCM. Previous studies show that the best educational results were obtained when farmers visited each other and, together with experts, discussed ways of improving their milking technique (Vaarst et al. 2007; Byarugaba et al. 2008).

This study also noted that well-functioning and healthy herds existed in the same livelihood as less healthy herds, which could serve as icons of success to use as role models for poorly functioning herds. However, further research is needed to investigate the prevalence of clinical mastitis in Uganda in order to obtain a more comprehensive picture of the current mastitis situation.

Acknowledgments First of all, I wish to express my gratefulness to the MFS scholarship and SIDA and Gulli Strålfeldts fond, whose grant partly supported this work. Special tanks should be directed to my supervisors in Uganda: Maria-Goretti Nassuna-Musoke and David O. Owiny at the Faculty of Veterinary Medicine at Makerere University. I am also most thankful to Theodoros Ntallaris for his valuable support in the field work. Furthermore, I owe the farmers of peri-urban Kampala who participated in the study an enormous thank you. This also applies to the help of Patrice Humblot, for the contribution made in the statistical analysis, as well as Mattias Perzon for language and text revision. For the help with the laboratory work, I thank Susanne André, Maria Finn, and all staff at the mastitis laboratory at SVA. Lastly, I thank Björn Bengtsson at the Department of Animal Health and Antimicrobial Strategies at SVA for his contribution to the antibiotic resistance analyses.

Open Access This article is distributed under the terms of the Creative Commons Attribution License which permits any use, distribution, and reproduction in any medium, provided the original author(s) and the source are credited. 


\section{References}

Andersson, I., Andersson, H., Christiansson, A., Lindmark-Månsson, H., Oskarsson, M., Persson, Y. \& Widell, A., 2011. Systemanalys Celltal. Stockholm: Svensk Mjölk Forskning. Nr. 7091

Bitew, M., Tafere, A. and Tolosa, T., 2010. Study on Bovine Mastitis in Dairy Farms of Bahir Dar and its Environs, Journal of Animal and Veterinary Advances, 9 (23), 2912-2917

Byarugaba, D. K., 2004. A view on antimicrobial resistance in developing countries and responsible risk factors, International Journal of Antimicrobial Agents, 24:2, 105-110

Byarugaba, D. K., Nakavuma, J. L., Vaarst, M. and Laker, C., 2008. Mastitis occurrence and constraints to mastitis control in smallholder dairy farming systems in Uganda, Livestock Research for Rural Development 20:1

Clinical and Laboratory Standards Institute. 2007. Performance Standards for Antimicrobial Susceptibility Testing; Seventeenth Informational Supplement. CLSI document M100-S17. Wayne Pennsylvania, USA:, 27:1 1-182 (ISBN 1-56238-625-5)

FAO - Food and Agriculture Organization of the United Nations. A. [online](2011-07-20) Accessible: http://www.fao.org/countries/ 55528/en/uga/ [2011-12-29]

FAO - Food and Agriculture Organization of the United Nations. C., 2011. World Livestock 2011 - Livestock in food security, Rome, FAO

Franklin, A. and Wierup, M., 1982. Evaluation of the sensitive method adapted for antimicrobial drug susceptibility testing in veterinary medicine, Veterinary Microbiology, 7, 447-454

Gianneechini, R., Concha, C., Rivero, R., Delucci, I. and Moreno López, J., 2002. Occurrence of Clinical and Sub-Clinical Mastitis in Dairy Herds in the West Littoral Region in Uruguay, Acta Veterinaria Scandinavivca, 43, 221-230

Godkin, A., Leslie, K. and Martin W., 1990. Mastitis in bulk tank milk culture in Ontario. Highlights, 13(2), 13-16

Harouna, A., Zecchini, M., Locatelli, C., Scaccabarozzi, L., Cattaneo, C., Amadou, A., Bronzo, V., Marichatou, H., Boettcher, P. J., Zanoni, M. G., Alborali, L. and Moroni, P., 2009. Milk hygiene and udder health in the periurban area of Hamidallaye, Niger, Tropical Animal Health and Production, 41, 705-710

Hogan, J., 2005. Human Health Risks Associated with High SCC Milk. In: Proceedings of the British Mastitis Conference 2005, Warwickshire, U.K.

Joshi, S. and Gokhale, S., 2006. Status of Mastitis as an Emerging Disease in Improved and Periurban Dairy Farms in India, Annals of the New York Academy of Sciences, 1081, 74-83

Kader, M. A., Samad, M. A. and Saha, S., 2003. Influence of host level factors on prevalence and economics of sub-clinical mastitis in dairy cows in Bangladesh, Indian Journal of Dairy Science, 56, 235-240.

Kintu, A., Byarugaba-Karuhize, D. and Nalwanga, D. K., 2000. Mastitis in Periurban Zerograzing Dairy Farming around Kampala, Uganda Veterinary Journal, 6, 45-50

Mdegela, R. H., Ryoba, R., Karimuribo, E. D., Phiri E. J., Løken, T., Reksen, O., Mtengeti, E. and Urio, N. A., 2009. Prevalence of clinical and subclinical mastitis and quality of milk on smallholder dairy farms in Tanzania, Journal of the South African Veterinary Association, 80:3 $163-168$
Mellenberger, R. and Roth, C. J., 2000. California Mastitis Test (CMT), Fact Sheet, Dept. of Animal Sciences, Michigan State University and Dept. of Dairy Science, University of Wisconsin-Madison.

Mungube, E. O., Tenhagen, B. A., Regassa, F., Kyule, M. N., Shiferaw, Y., Kassa, T. and Baumann, M. P. O., 2005. Reduced milk production in udder quarters with subclinical mastitis and associated economical losses in Crossbred Dairy Cows in ethiopia, Tropical Animal Health and Production, 37, 503-512

Nakavuma, J., Byarugaba, D. K., Musisi, L. N. and Kitimbo, F. X., 1994. Microbiological Diagnosis and Drug Resistance patterns of infectious causes of mastitis, Uganda Journal of Agricultural Sciences, 2 , 22-28

Neelesh Sharma, Gyu Jin Rho, Yeong Ho Hong, Tae Young Kang, Hak Kyo Lee, Tai-Young Hur and Dong Kee Jeong, 2012. Bovine Mastitis: An Asian Perspective, Asian Journal of Animal and Veterinary Advances, 7, 454 476.

NMC., 2004. Microbiological Procedures for the Diagnosis of Bovine Udder Infection and Determination of Milk Quality.

Okello-Uma, I. and Gibson, D. I., 1976 Study of means control of Bovine mastitis in Uganda; 2: Post milk teat dip, East African Agricultural and Forestry Journal, 41:3, 266-270

Persson, Y., Nyman, A.-K. J. and Grönlund-Andersson, U., 2011. Etiology and antimicrobial susceptibility of udder pathogens from cases of subclinical mastitis in dairy cows in Sweden, Acta Veterinaria Scandinavivca, 53:36

Rabbani, A.F.M.G. and Samad, M.A., 2010. Host Determinants Based Comparative Prevalence of Subclinical Mastitis in Lactating Holstein-Friesian Cross Cows and Red Chittagong Cows in Bangladesh, Bangladesh Journal of Veterinary Medicine, 8(1), 1721

Saloniemi, H., 1995. Use of somatic cell count in udder health work. In: Sandholm, M., Honkanen-Buzalski, T., Kaartinen, L. and Pyörälä, S. (ed.) (University of Helsinki, Faculty of Veterinary Medicine), The Bovine Udder and Mastitis, 105-110. Gummerus Kirjapaino, Jyväskylä. (ISBN 951-834-047-1)

Schalm, O. W., Coroll, E. J. and Jain, N. C., 1971. Bovine Mastitis. Lea and Febiger. Philadelphia, PA, USA

Schalm, O. W. and Noordlander, D. O., 1957. Experiments and observations leading to developments of the Californian mastitis test, Journal of American Veterinary Medicine Association, 30, 199-204

Seegers, H., Fourichon, C. and Beaudeau, F., 2003. Production effects related to mastitis and mastitis economics in dairy cattle herds, Veterinary Research, 34(5), 475-491

Singh, P. J. and Sing, K. R., 1994. A study of economic losses due to mastitis in India, Indian Journal of Dairy Science, 47, 265-272

Sveriges Veterinärmedicinska Sällskap, 2011. Riktlinjer för användning av antibiotika till produktionsdjur, Husdjursektionen SVS. March 2011, pp. 15

Uganda Bureau of Statistics, Livestock census report, 2008. Accessible: http://www.agriculture.go.ug or www.ubos.org [2012-11-26]

Vaarst, M., Byarugaba, D. K., Nakavuma, J. and Laker, C., 2007. Participatory Livestock Farmer Training for improvement of animal health in rural and peri-urban smallholder dairy herds in Jinja, Uganda, Tropical Animal Health and Production, 39, $1-11$ 